INTERNATIONAL JOURNAL OF ENVIRONMIENT

Volume-9, Issue-2, 2020

ISSN 2091-2854

Received: 23 July 2020

Revised: 2 November 2020

Accepted: 3 November 2020

\title{
HUMAN-WILDLIFE CONFLICT AND ITS IMPLICATION FOR CONSERVATION AT SUNDARPUR, UDAYAPUR, EASTERN NEPAL
}

\author{
Manoj Pokharel ${ }^{1}$ and Chandramani Aryal ${ }^{1,2}$ [D \\ ${ }^{1}$ Department of Environmental Science, Tri-Chandra Multiple Campus, Kathmandu, Nepal \\ ${ }^{2}$ Environment Protection and Study Center, Kathmandu, Nepal \\ *Corresponding author: aryal.mani@gmail.com
}

\begin{abstract}
Local people are the major stakeholders of biodiversity conservation. Human-wildlife conflict (HWC) could result in a negative attitude of the general public towards wildlife adding challenges for conservation. This is more applicable in the landscapes which are outside the protected area (PA) coverage. But, the majority of HWC related studies in Nepal have centered on PAs and their peripheries. This study documents the prevailing situation of HWC in Sundarpur of Udayapur district that shelters some HWC prone wildlife species, while situating outside PA. Data about conflict and people's perception of wildlife conservation was collected using household surveys supplemented by key informant interviews and direct observation. Monkeys (93\%, $\mathrm{n}=93$ ) and elephants $(86 \%, \mathrm{n}=86)$ were found to be the major animals involved in the conflict, mostly resulting in crop raiding, the major form of conflict as reported by $(95 \%, n=95)$ of respondents. Livestock depredation cases were mostly by common leopard $(84 \%, \mathrm{n}=21)$ and sloth bear was involved in the majority of human attack cases $(90 \%, n=9)$. The results showed increasing trend of conflicts for elephants $(63 \%, \mathrm{n}=63)$ and monkeys $(73 \%, \mathrm{n}=73)$, while declining trend for sloth bear $(64 \%, \mathrm{n}=64)$, wild boar $(85 \%$, $\mathrm{n}=85)$, and leopard $(46 \%, \mathrm{n}=46)$. People believed the natural attraction of wildlife towards crops and livestock to be the major driving factor of conflict. Majority of respondents had a positive attitude towards wildlife conservation. However, implementation of community based conflict management strategies, robust compensation schemes along with conservation education programs are highly essential to achieve desired conservation success.
\end{abstract}

Keywords: crop raiding, human attack, human-wildlife conflict, livestock depredation, people's perception

DOI: http://dx.doi.org/10.3126/ije.v9i2.32750

Copyright (C2020 IJE

This work is licensed under a CC BY-NC which permits use, distribution and reproduction in any medium provided the original work is properly cited and is not for commercial purposes 


\section{Introduction}

Biodiversity Conservation involves the tradeoff of conflicting interests of multiple stakeholders' including local people. Proper integration of the interests of the local people is vital for sustainability of biodiversity conservation related policy implementation (Bhattarai et al., 2017). In the past, when human population was low, the frequency and severity of the interaction between human and wildlife were low. As human population is continuously increasing, the use of wildlife habitat by humans is increasing simultaneously, creating pressure on wildlife populations, resulting in frequent interactions between the two (Barua et al., 2013). Such interactions are often negative and present a complex challenge for the successful conservation of biodiversity throughout the world (Acharya et al., 2016; Treves and Karanth, 2003). This issue, commonly known as human-wildlife conflict (HWC), not only threatens the survival of wildlife species, but also creates severe socio-economic tension among people, which may have a long-term effect on human wellbeing (Barua et al., 2013; Dickman, 2010). The situation is more prevalent in developing regions of the world, where competition for natural resources between humans and wildlife is greatest (Barua et al., 2013; Seoraj-Pillai and Pillay, 2017). Understanding the social context of the human-wildlife conflict along with material impacts is essential to design and implement effective mitigation measures (Redpath et al., 2013).

Nepal has made significant progress in the front of biodiversity conservation both within and outside of protected areas (PAs), with which the incidences of HWC are reported to be increasing (Acharya et al., 2016; Gurung et al., 2008). Most HWC cases in Nepal have been reported from the Tarai region (Bhattarai and Fischer, 2014; Gurung et al., 2008; Shrestha, 2007). This is probably due to the presence of high density wildlife populations in fragmented forest patches surrounded with extensive human settlements (Acharya et al., 2017; Shrestha, 2007). A recent study shows that areas outside PAs of Nepal are turning into HWC hotspots, with elephants and leopards at the forefront of conflict causing species indicated by the frequencies and fatalities resulting from the conflicts (Acharya et al., 2016).

The eastern Tarai region, being feebly represented in the current system of PAs is a case in point. Occurrence of conflict prone species like common leopard, wild boar, rhesus macaque and sloth bear, and regular movement of wild elephants as part of their historical migratory route (Jnawali et al., 2011; Neupane et al., 2013) has made this part of the country vulnerable to HWC. The region, however, has received less scientific attention because the majority of HWC investigating studies are focused on PAs (Bhattarai and Fischer, 2014; Gurung et al., 2008; Studsrød and Wegge, 1995). We believed the Sundarpur area of Udayapur district to provide an ideal case study to understand the scenario of HWC in eastern Tarai. Not only because the region lies in eastern Tarai, but it also shelters one of the important sloth bear populations in the country (Jnawali et al., 2011) along with the presence of above mentioned species that are susceptible to getting involved in HWC. 
This study was designed in a way to provide baseline information about the situation of HWC in Sundarpur having specific aims to (i) document major forms of HWC that are prevalent in the area and major animals involved in them, (ii) assess the trend and driving forces of HWC according to the perception of local people, and (iii) provide insight into the attitude of local people towards conservation of threatened wildlife species which are involved in the conflict.

\section{Materials and methods}

\subsection{Study area}

The study was carried out in Sundarpur of Chaudandigadhi Municipality, which lies in Udayapur district of eastern Nepal (Figure 1). It is one of four urban municipalities of the Udayapur district with an estimated total population of 48,574. It covers an area of $283.78 \mathrm{~km}^{2}$ and contains a total of 10 wards. Sundarpur lies in ward number 5 of the municipality with a total population of 5673 individuals in around 1372 households (Chaudandigadhi Municipality, 2020). The region lies in the lower tropical ecological zone where the average annual temperature ranges from $23-25.5^{\circ} \mathrm{C}$ with average annual precipitation falling in the range of $1,159-$ $2,827 \mathrm{~mm}$ (Lillesø et al., 2005). The vegetation of this area is dominated by Shorea robusta, while Dalbergia sisso, Acacia catechu, and Bombax ceiba are some other common tree species found in the region. Major mammalian faunas of this area are Barking deer (Muntiacus muntjak), Wild boar (Sus scrofa), Rhesus macaque (Macaca mulatta), Common leopard (Panthera pardus), Gaur (Bos gaurus), Asiatic elephant (Elephas maximus), Golden jackal (Canis aureus), Jungle cat (Felis chaus), and Sloth bear (Melursus ursinus) (Aryal et al., 2020; Khadka et al., 1997). 


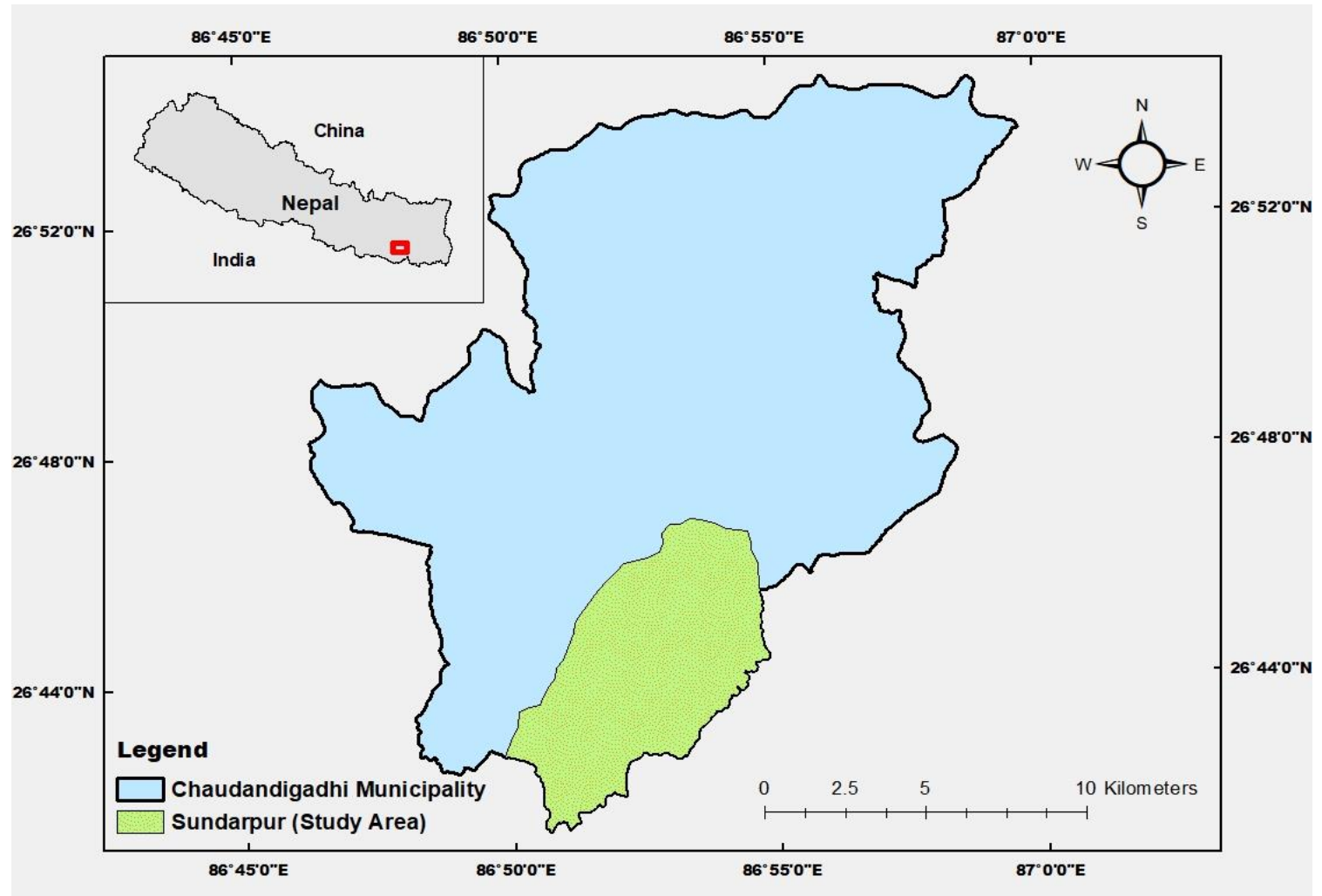

Figure 1: Map of study area

\subsection{Survey design and Data collection}

\subsubsection{Household surveys}

Hundred households of Sundarpur representing around 7\% of total $(n=1372)$ households were surveyed during October 2018 using semi-structured set of questionnaires for data collection (White et al., 2005). The households were chosen based on systematic sampling method (Newing et al., 2010), because our survey was focused to the communities living closer to forest boundaries that were more likely to face HWC incidents, for which no census data was available to conduct simple random sampling. In survey every fourth household was surveyed after randomly selecting the first one. The semi-structured questionnaire consisted questions of socio-economic background of the respondent, experiences of crop and livestock depredation, human injury, death, and property damaged by wildlife along with mitigation measures adopted for minimizing the conflicts. There were also questions related to people's perception on driving forces and trend of conflict along with their attitude towards conservation of threatened species that are involved in the conflict. Information on crop raiding was recorded for two years (2017-2018), livestock depredation and property damage for five years (2014-2018), and human injury and death for eleven years (2008-2018).

\subsubsection{Key Informant Interviews}

Household survey was supplemented by Key Informant Interviews (KII) $(n=5)$ with community and sector forest officials (Sherchan and Bhandari, 2017; Bhattarai and Fischer, 2014). The questionnaire administered 
to key informants contained questions related to compensation schemes that are provided for HWC victims and the role played by them in conservation of wildlife present in the area.

\subsubsection{Direct observation}

Field observation of the recent incidents ( $<7$ days) of crop raiding and observation of wound marks left by sloth bear attacks in the victim's body, was carried out whenever possible to verify and enhance the validity of the obtained data. All the observations were made after getting consent from the respondents.

\subsection{Data analysis}

Data analysis was performed using statistical software JASP. Most of the data was analyzed using descriptive statistics (such as mean, standard deviation, and percentage). Chi-square test of goodness of fit was used for determining if the observed difference in frequencies for a single variable is statistically significant. Whereas, differences among the wildlife species in the frequency of crop raiding, differences among different crops in being damaged by wildlife, differences on people's perception regarding the trend and driving factors of HWC according to wildlife species, and differences within gender on attitude towards wildlife conservation was analyzed using Chi-square test of independence. Cramer's V was used to evaluate the strength of the relationships that were statistically significant $(\mathrm{P}<0.05)$.

\section{Results}

\subsection{Socio-economic characteristics}

Out of the total $(\mathrm{n}=100)$ respondents that were interviewed, $(30 \%, \mathrm{n}=30)$ were female and $(70 \%, \mathrm{n}=70)$ were male. Average family size of the respondents was $5.25(\mathrm{SD}=1.75)$ persons. The eldest and youngest respondents were 87 and 17 years of age respectively and the mean age was 45.68 (SD=16.57). Most of the respondents i.e. $(90 \%, \mathrm{n}=90)$ were farmer, while $(4 \%, \mathrm{n}=4)$ were labor, $(3 \%, \mathrm{n}=3)$ were businessman, $(2 \%$, $\mathrm{n}=2)$ were teacher, and $(1 \%, \mathrm{n}=1)$ were carpenter. People not having agriculture as major occupation were also involved in farming to some extent as $100 \%$ of the respondents owned farmland. Rice, maize, wheat, millet, and vegetables were most commonly cultivated crops with cow, buffalo, ox, and goat as major livestock hold by the people of the study area.

\subsection{Human-wildlife conflict}

The study revealed that ninety-seven percent $(n=97)$ of the sampled households were having problems of one or another form with the wild animals. Monkeys $(93 \%, \mathrm{n}=93)$ and elephants $(86 \%, \mathrm{n}=86)$ were major animals involved in the conflict followed by wild boar (24\%, $n=24)$, leopard $(19 \%, n=19)$, sloth bear $(17 \%, n=17)$, porcupine $(12 \%, \mathrm{n}=12)$, peacock $(9 \%, \mathrm{n}=9)$, and jackal $(3 \%, \mathrm{n}=3)$. Significant portion of respondents $(95 \%$, 
$\mathrm{n}=95$ ) believed crop depredation to be the major form of conflict they have been facing. However, other consequences of conflict - livestock depredation $(23 \%, n=23)$, property damage $(22 \%, n=22)$, and human injury $(10 \%, \mathrm{n}=10)$ were also recorded during the study.

Crop depredation in the area was primarily due to monkeys, elephants, and wild boars leading to a total of 494 crop raiding incidents in two years. Thus, these species were only taken into account for further analysis. Significant difference was observed among the three wildlife species in terms of total crop raiding events $(\chi 2=46.7, \mathrm{df}=2, \mathrm{p}<0.001)$. Monkeys were reported for highest $(43 \%, \mathrm{n}=210)$ of crop raiding incidents, followed by elephants (38\%, $\mathrm{n}=190)$, and wild boar $(19 \%, \mathrm{n}=94)$. Different crops cultivated in the area had significant differences in the degree of being damaged by wildlife $(\chi 2=292.78, \mathrm{df}=7, \mathrm{p}<0.001)$. Paddy $(32 \%$, $\mathrm{n}=158$ ) was the most commonly raided crop along with maize $(21 \%, \mathrm{n}=104)$, wheat $(17 \%, \mathrm{n}=86)$, millet $(10 \%, n=49)$, and others $(20 \%, n=97)$. The crop raiding pattern also varied significantly according to the wildlife species $(\chi 2=101.08, \mathrm{df}=14, \mathrm{p}<0.001)$. Elephants mainly raided paddy $(50 \%, \mathrm{n}=80)$ and wheat $(59 \%$, $\mathrm{n}=51$ ), while maize was mostly depredated by monkeys $(61 \%, \mathrm{n}=64)$ (figure 2). Elephants were also responsible for damaging property of $(22 \%, \mathrm{n}=22)$ households, counted for the time period of five years. House $(41 \%, n=9)$ was most commonly damaged property which was followed by storehouse of grains $(36 \%, n=8)$, and kitchen $(23 \%, \mathrm{n}=5)$.

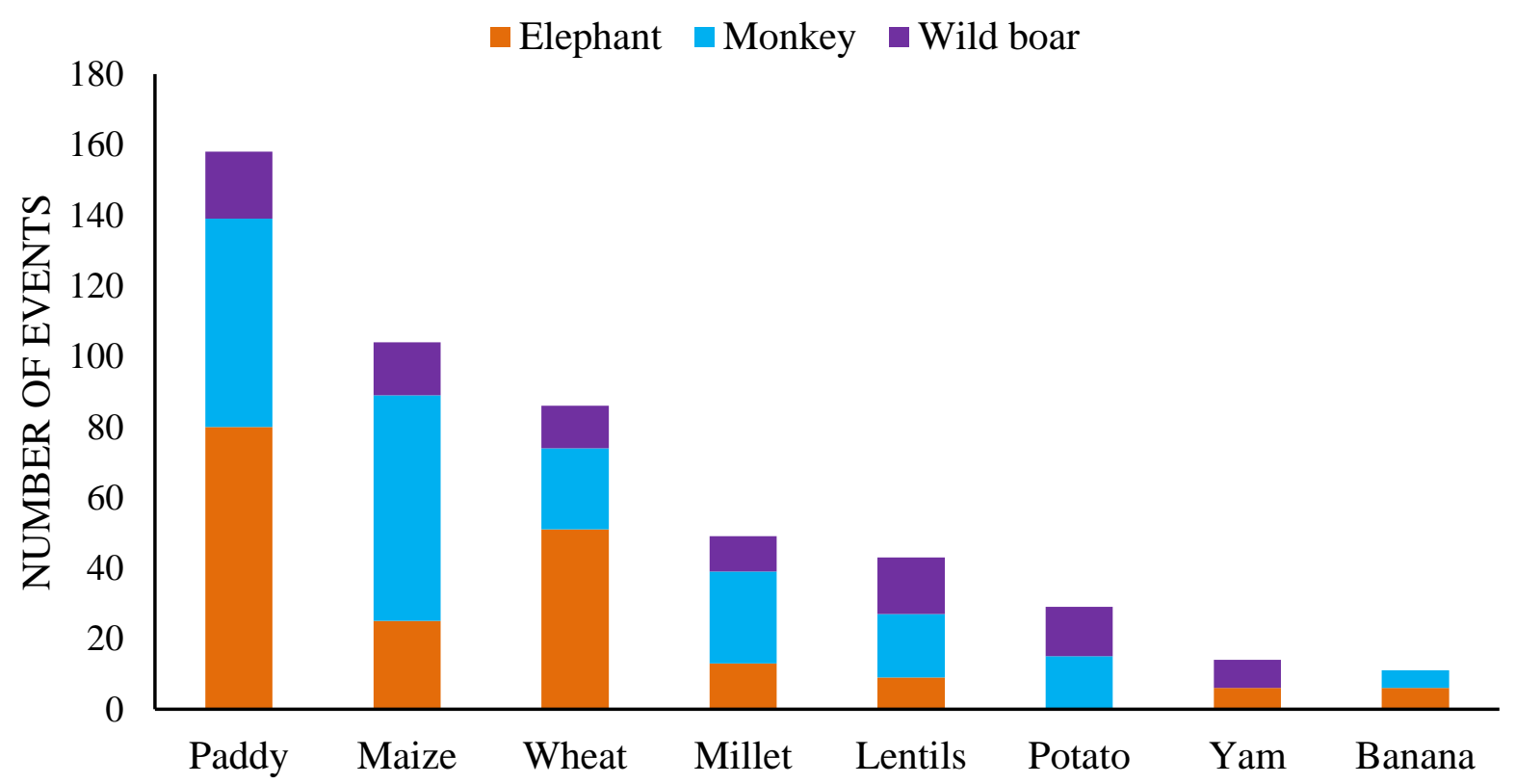

Figure 2: Major crops and the degree of damage caused by wild animals in Sundarpur

Among the twenty-five cases of livestock depredation, majority were by common leopard $(84 \%, \mathrm{n}=21)$ and then by jackal $(16 \%, n=4)$. Goat $(68 \%, n=17)$ was most commonly raided livestock followed by cow calf 
$(20 \%, \mathrm{n}=5)$, poultry $(8 \%, \mathrm{n}=2)$, and adult cow $(4 \%, \mathrm{n}=1)$. Leopard mostly killed goats accounting for $(88 \%$, $\mathrm{n}=15$ ) of the total goat kills and two goat depredations were attributed to jackal. With five reported cases of depredation, cow calf was the second most target of leopard, and the depredation of adult cow was reported only once. Jackal was found to be responsible for all of the reported poultry raiding cases (i.e. $n=2$ ). Livestock depredation due to leopard mostly occurred in forest $(86 \%, \mathrm{n}=18)$ but had also occurred inside settlement $(9 \%$, $\mathrm{n}=2)$ and near to settlement $(5 \%, \mathrm{n}=1)$.

Ten different incidents of human attacks by wildlife species was documented in Sundarpur during (20082018) accounting for an average of $0.9(\mathrm{SD}=0.83)$ attacks per year. Nearly all of the attacks $(90 \%, \mathrm{n}=9)$ was due to sloth bear and only one attack was by leopard. The attacks by sloth bear were almost exclusively inside forest $(89 \%, \mathrm{n}=8)$ and the only attack outside forest occurred in the riverbank close to settlement when the person was defecating. Victims of the sloth bear attack mostly belonged to age group 37-46 (56\%, $\mathrm{n}=5)$, followed by age group 47-56 (33\%, $n=3)$, and 57-66 (11\%, $n=1)$. Attacks were common during afternoon $(56 \%, n=5)$ than in the moming $(33 \%, n=3)$ and evening $(11 \%, n=1)$, where a large percentage of victims $(78 \%, \mathrm{n}=7)$ were male and only $(22 \%, \mathrm{n}=2)$ were female. Bears involved in attack were often single $(67 \%$, $\mathrm{n}=6)$, followed by a mother bear with one cub $(22 \%, \mathrm{n}=2)$, and mother bears with two cubs $(11 \%, \mathrm{n}=1)$.

\subsection{Trend and Driving force of conflict}

People's perception on the trend of conflict differed significantly with the wildlife species $(\chi 2=265.52, \mathrm{~d} f=8$, $\mathrm{p}<0.001)$. Large majority of people reported significant increase in conflict with monkeys $(73 \%, n=73)$ and elephants $(63 \%, n=63)$, while decreasing trend of conflict with wild boar $(85 \%, n=85)$, sloth bear $(64 \%, n=64)$, and leopard $(46 \%, n=46)$. Similarly, significant portion of people perceived natural attraction towards crops/livestock to be the major driving factor of conflict for elephants $(40 \%, \mathrm{n}=40)$, monkeys $(38 \%, \mathrm{n}=38)$, and leopards $(40 \%, \mathrm{n}=40)$ and increased animal population was believed to be the major driving factor for conflict with sloth bear $(46 \%, \mathrm{n}=46)(\chi 2=68.8, \mathrm{df}=9, \mathrm{p}<0.001)$ (Figure 3). Cramer's V was found to be 0.239 meaning nearly $24 \%$ species wise variations in causes of conflicts are explained by the data. Shrinking wildlife habitat and inefficient protection measures from wildlife were other factors that respondents believed of driving HWC (Figure 3). 


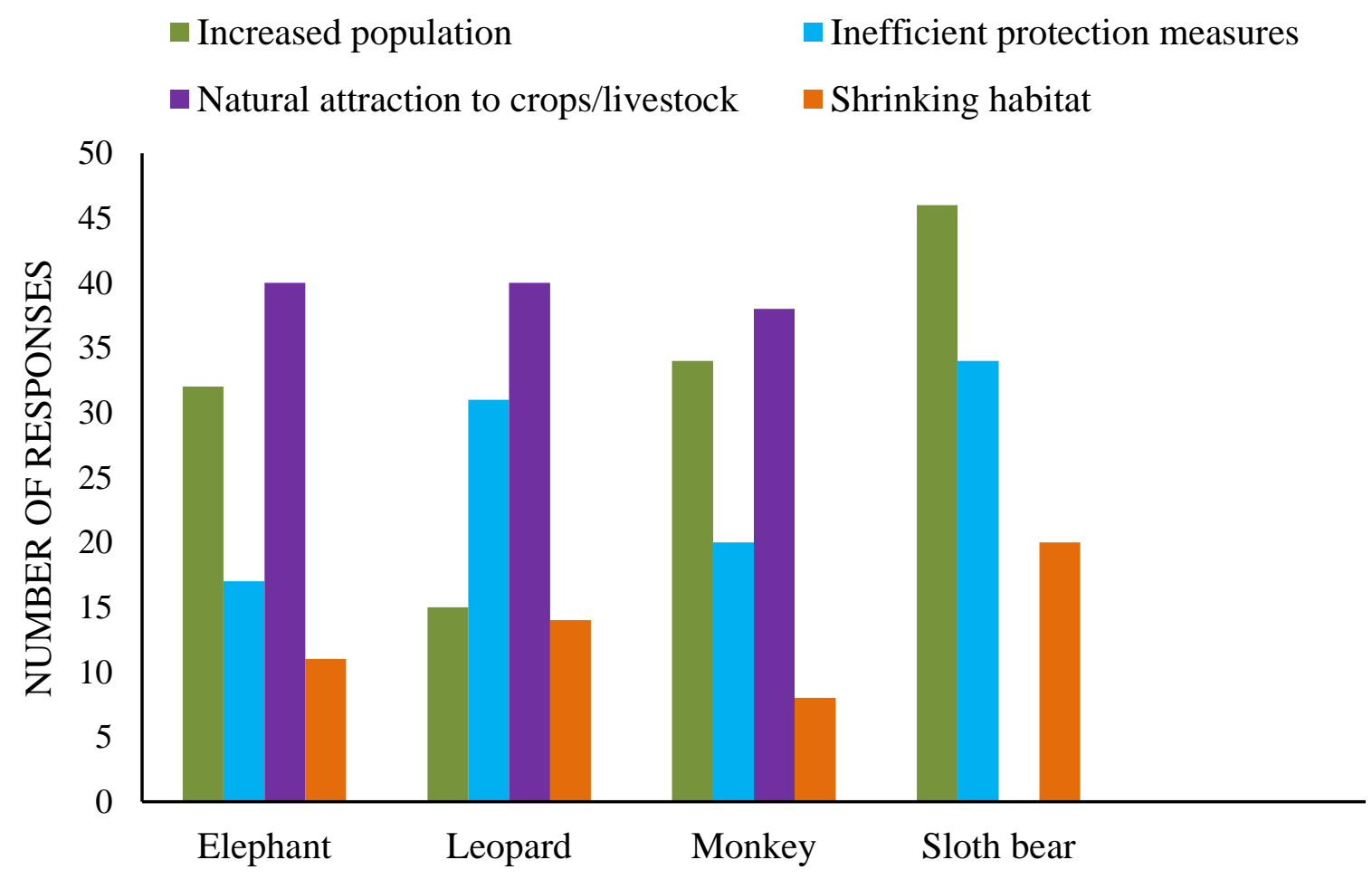

Figure 3: People's perception on the driving factors of HWC for different species

\subsection{People's attitude towards wildlife conservation}

Majority of respondents showed positive attitude for conservation of all the three threatened species that were considered in the study. The conservation of elephant was favored by the majority of the respondents (74\%, $\mathrm{n}=74)$ compared to sloth bear $(42 \%, \mathrm{n}=42)$ and leopard $(41 \%, \mathrm{n}=41)(\chi 2=13.46, \mathrm{df}=2, \mathrm{p}=0.001)$ (Figure 4$)$. Analyzing the relationship between respondents' gender and their attitude towards conservation, it was found that male $(84.2 \%)$ were more positive for elephant conservation than female $(50 \%)(\chi 2=12.86, \mathrm{df}=3$, $\mathrm{p}=0.005)$. Likewise, conservation of leopard was also most favored by male (42.9\%) than that of female $(36.7 \%)(\chi 2=9.333, \mathrm{df}=3, \mathrm{p}=0.025)$. In case of sloth bear, although male (44.3\%) seem more positive for conservation compared to female (36.7\%), this difference was not found to be significant $(\chi 2=2.317, \mathrm{df}=4$, $\mathrm{p}=0.678$ ). The Carmer's V for the relation between the gender and perception about the elephant was 0.359 while that with leopard was 0.305 meaning nearly $36 \%$ of the variations in the perception about the elephant and $30.5 \%$ of variation in perception about leopard are explained by gender. Both indicate that gender and perception towards the leopard and elephant have medium association. 


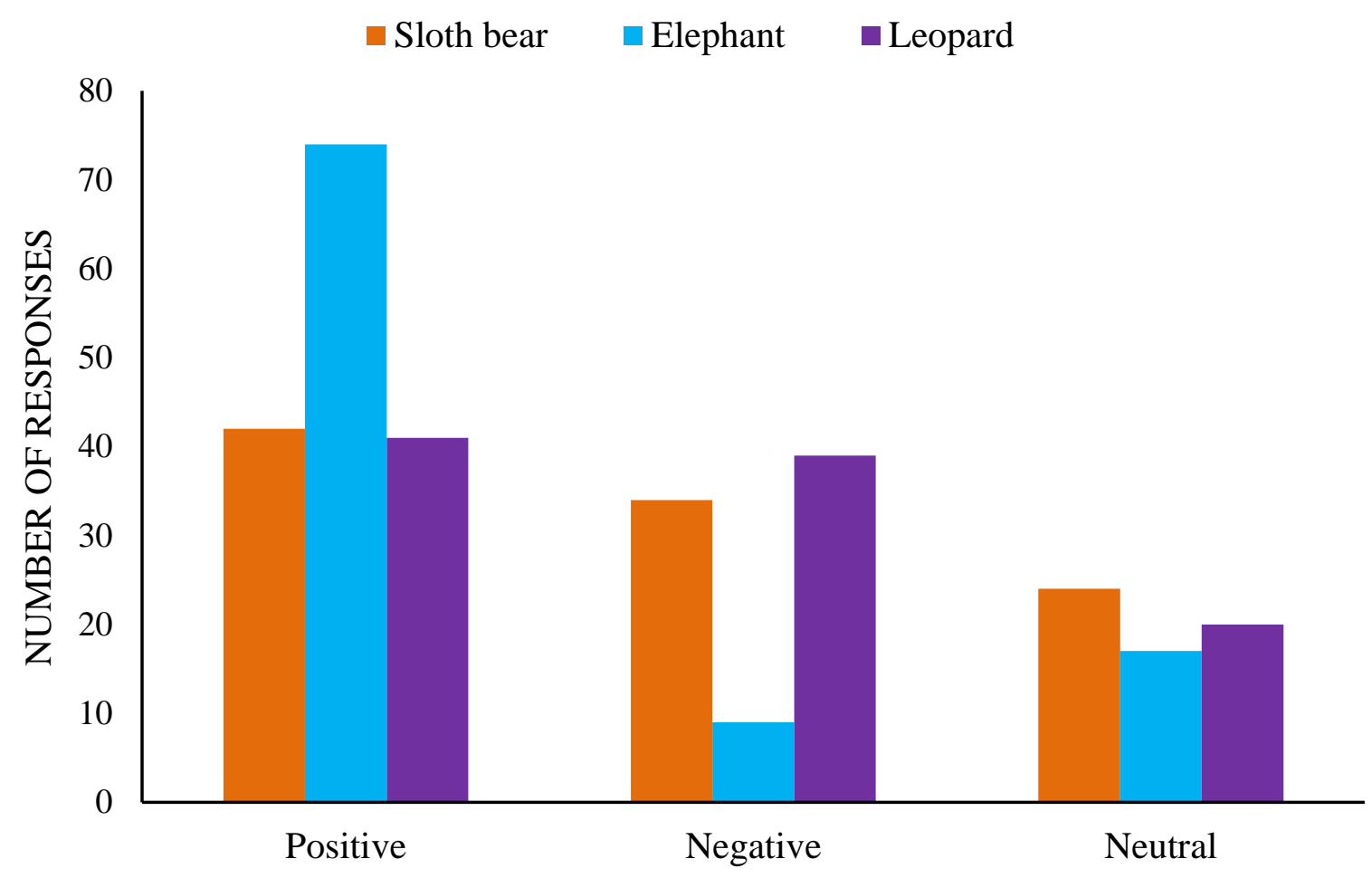

Figure 4: People's attitude towards wildlife conservation

\section{Discussion}

Understanding the pattern and process of human wildlife conflicts are vital from the conservation perspectives (Acharya et al., 2016). Eastern Nepal, despite being the hotspots of human wildlife conflicts, they are hardly explored in the past. The study reported that crop raiding was the most significant conflict though livestock depredation and human injury due to wildlife are also reported in the area. The trend of conflict and perception of local people towards wildlife involved in conflict was different for different species. This research will provide baseline for evaluation of future dynamics of the conflicts in the area and will help to initiate conservation management outside protected areas.

\subsection{Human-wildlife conflict}

The results indicate that, with the majority of residents involved in farming, the people of Sundarpur have largely been affected by the consequences of HWC. This has surely resulted in decreased livelihood opportunities for local people, which is the case in many of the developing countries (Seoraj-Pillai and Pillay, 2017). Crop raiding by wild animals was by far the most serious problem here, showing similarity with other studies (Studsrød and Wegge, 1995; Shrestha, 2007; Karanth et al., 2012). The large scale damage was due to elephants, while monkeys were the most frequent raiders followed by wild boar. Similar behavior of these animals has been reported from other parts of their occurrence range (Fernando et al., 2005; Pandey et al., 
2016; Richard et al., 1989). The inference of our study that crops like paddy, wheat, and maize are more likely to be damaged by wildlife, and elephants generally prefer paddy and wheat is somewhat parallel to the findings of other studies (Shrestha, 2007; Thapa, 2010). However, it has been observed that wildlife can raid any palatable crops based on the crops availability (Hoare, 1999; Thapa, 2010). Hence, the widespread cultivation of paddy, maize, and wheat compared to other crops in our study area could have contributed to the greater reporting of these crops being raided. Moreover, the higher palatability and nutrients availability in cultivated crops in comparison to wild vegetation, could attract wildlife species, especially megaherbivores like elephants to crop fields once they get habituated (Sukumar, 1990). Even though the majority of respondents believed crop raiding by wild boar is decreasing, it still ranked third among the most conflict causing species in Sundarpur. This can reveal the severity of conflict people were facing with this species before, which not only feeds on crops, but cause significant damage to the whole plant and agricultural land by uprooting and digging (Thapa, 2010). Illegal hunting of the herbivore species including wild boar was reported to be rampant in Triyuga area (Aryal, 2016) of which Sundarpur is part. Excessive hunting might have reduced the population of the wild boar and thus resulted in a decrease in conflict incidences. This makes sense in the light of existing literature that mentions regulated hunting of wild boar to be effective for the management of its population size and reduce the conflict (Pandey et al., 2016).

Leopard was the principal livestock predator of the area. This is an analogy with studies from different parts of the world where leopards co-exist with humans (Constant et al., 2015; Kabir et al., 2014; Mir et al., 2015). Leopards are known to prefer moderately sized prey species as they can be easily dragged and hid in safe place after killing (Bibi et al., 2013). Depredation of goats and cow calves to most of the extent as documented in our study could be due to this feeding preference of common leopard. We recorded most livestock depredation events by leopards inside the forest and only a few near or within settlements. This was because livestock grazing inside the forest was widespread around Sundapur, which only decreased in intensity after imposing grazing prohibition inside some of the community forests in recent years from the authorities. The decreasing trend of conflict with leopard could be, to some extent, due to this prohibition. However, due to limited prey resources, both wild and domestic, inside the forest, leopards might start visiting areas nearby settlement for food and the situation might worsen with time. Thus, a combination of measures including, separation of grazing zone quite away from leopard habitat, effective herding practices with constant attention to more vulnerable livestock groups, secured night time protection of livestock, use of livestock guarding dogs, and removal of bushes and vegetation around settlements that can serve as hiding places for leopard (Athreya et al., 2013; Constant et al., 2015; Inskip and Zimmermann, 2009; Kabir et al., 2014), could be practiced in the area to minimize the intensity of conflict with leopards in the long run. 
In addition to livestock depredation, leopards are well known for causing human casualties throughout their range in Nepal (Acharya et al., 2016), but the intensity in Sundarpur was found to be low and sloth bear was responsible for most of such cases. The sloth bear is famous for its aggressiveness and low tolerance towards humans (Can et al., 2014). People of Sundarpur bearing injuries from sloth bear attack must have been the victim of this aggressive behavior of sloth bear. Such confrontations with sloth bear are common in areas having obstructed visibility, where both humans and sloth bear encounter in a surprising manner (Garcia et al., 2016; Yoganand et al., 2005). Avoidance of areas having thick vegetation cover and any other features that can lead to sudden encounters with bear are essential to reduce conflict (Yoganand et al., 2005), which is equally applicable to Sundarpur area. Additionally, visiting forest in larger groups rather than alone or in small groups can also reduce the chances of attacks, as more people are likely to make louder noise making bears aware of human presence and thereby preventing encounters (Bargali et al., 2005; Garcia et al., 2016). More men were found to be the victim of sloth bear attacks compared to women. The finding is similar to other studies and must be due to more involvement of males to work inside forest, generally alone, while females, when engaged in such activities, mostly travel in groups (Bargali et al., 2005; Garcia et al., 2016). Sloth bears, although, crepuscular or nocturnal in habit, can be active during daylight based on different phases of their life cycle, especially during sub-adulthood and motherhood (Joshi et al., 1999). The majority of attacks that were recorded during the afternoon must be due to the overlap in activity patterns between such bears and humans, who mostly visit forest in the same time in the study area. Yoganand et al. (2006) documented conflict with sloth bear in India to occur predominantly in areas having high bear abundance. This occurs in a contradiction to this study where people perceived decrement in sloth bear conflict despite of the increased population. However, it has also been reported that the frequency of conflict with sloth bear is not largely associated with bear abundance, but with the degree of use of forest by people (Yoganand et al., 2006). Thus, as mentioned by key respondents, increment in forest area through restoration programs, prohibition on hunting and grazing, and regular patrolling of forest by forest officials in recent time could have minimized human activities in forest resulting in reduced conflict with sloth bear.

\section{Compensation and mitigation measures}

Conflict with wildlife was prevalent in Sundarpur, but the use of appropriate mitigation measures was found to be lacking. Crop guarding, using scarecrows in the crop field, lighting fire, firecrackers, and group shouting were the measures adopted by local people to minimize the conflict. Even though such methods have been utilized in other parts of the country (Neupane et al., 2013; Studsrød and Wegge, 1995; Thapa, 2010), it is essential to test the effectiveness of these methods and introduce new effective measures in Sundarpur area to minimize the intensity of HWC. Compensation for the damage caused by wildlife is another means to mitigate 
HWC (Karanth \& Nepal, 2012; Kusi et al., 2020). Community and sector forest officials of Sundarpur reported to provide timber and firewood as compensation for most wildlife damage and cash was known to be provided only for human casualties. The majority of respondents were unsatisfied with this existing compensation scheme indicating a need for implementing more robust methods of compensation as mentioned in other studies (Karanth \& Nepal, 2012; Studsrød \& Wegge, 1995).

\subsection{People's attitude towards wildlife conservation}

The attitude of people towards wildlife and their conservation greatly influences the conservation success of the particular species, especially of the large and threatened mammals (Barua et al., 2013; Bhattarai \& Fischer, 2014). For people living in the vicinity of PAs, the benefit gained through ecotourism and community development programs can lead to a more tolerant attitude towards wildlife (Bhattarai \& Fischer, 2014; Karanth \& Nepal, 2012). Regardless of the unavailability of such benefit, the positive attitude shown by majority of people towards wildlife conservation in Sundarpur is highly appreciable. Among all the species, elephants gained widespread support for conservation from the local people. In the region having Hinduism as the predominant religion, this was linked with the religious sentiment attached to elephants, where they are worshipped as Lord Ganesh (Shrestha, 2007). A positive attitude towards other wildlife because of similar religious belief has been recorded from other parts of the country (Bhattarai and Fischer, 2014; Kusi et al., 2020). Furthermore, social factors are reported to play important role in shaping people's attitude towards wildlife (Dickman, 2010). The results of this study also indicated a significant role played by gender in shaping the attitude towards wildlife, with males more positive than females. Similar findings have been observed in studies both within (Bhattarai and Fischer, 2014; Kusi et al., 2020) and outside of Nepal (Mir et al., 2015; Røskaft et al., 2003). The reason behind this might be the fear associated with wild animals. Males who are mostly involved in outdoor activities might have frequent interactions with wild animals leading to reduced fear towards them and the case might be the opposite with women who tend to spend most of their time in indoor activities (Røskaft et al., 2003). Oppositely, women could be more fearful of attacks by wildlife because of their regular involvement in collecting forest resources (Bhattarai \& Fischer, 2014).

Even though in a small number, people who opposed conservation can, however, seriously hinder the conservation of the wildlife species by getting involved in different illegal activities as well as by influencing other people to develop a similar attitude (Mir et al., 2015). The conservation education programs are reported to foster a more positive attitude among local people towards wildlife conservation (Mir et al., 2015; Treves and Karanth, 2003). Thus, it is seen highly essential to establish community based conflict management strategies along with conservation education programs in Sundarpur. 


\section{Conclusions}

In the face of rapidly declining wildlife populations it has never been so urgent to address the emerging problems of conservation. Conservation interventions should not only be focused around protected areas, but also in areas where the habitat remains unprotected. This study depicts one such case from Sundarpur of eastern Nepal where the prevalence of HWC has caused a detrimental effect on both humans and wildlife of this region. The occurrence of species like monkeys, wild boars, and frequent visit of wild elephants have made crop raiding a major consequence of HWC in this region. Although the conflict in the forms of livestock depredation, property damage, and human injury were less intense than crop depredation, conflict management should be based on a holistic approach addressing all the problems for effective outcomes. Likewise, the introduction of robust mitigation and compensation measures for the damage caused by wildlife has the potential to greatly minimize the intensity of HWC in Sundarpur. Despite all, the positive attitude shown by the majority of respondents towards wildlife conservation and especially elephants makes us optimistic about the future of biodiversity conservation in this area. Hence, it is highly essential to start addressing the issues associated with HWC by recognizing the local community as a key stakeholder of the intervention. Besides, conservation outreach activities should also be launched to foster a more positive attitude among locals and increase their ability to co-exist with wildlife soundly.

\section{Conflict of interest}

Authors declare no conflict of Interest.

\section{Authors contribution statement}

Manoj Pokharel: Designed study, collected data, analyzed data, wrote draft and finalized draft.

Chandramani Aryal: Conceived and designed the study, analyzed data, revised the draft, supervised the research work and finalized manuscript.

\section{Acknowledgements}

We would like to acknowledge Asst. Prof. Mr. Kishor Kumar Maharjan, Head of Department of Environmental Science, Tri-Chandra Multiple campus, for approval of the proposal and administrative support to undertake this research work. Authors' would like to acknowledge Asst. Prof. Sanu Raja Maharjan and Bina Ghimire for their valuable input in prior to preparation of manuscript. We would like to acknowledge the Anonymous reviewers and editor for their valuable input in the manuscript which helped to enhance the quality of this manuscript. We are also grateful to all the faculty members of the Department of Environmental 
Science of Tri-Chandra Multiple Campus and the people of Sundarpur for their kind support leading to successful completion of this work.

\section{References}

Acharya, K. P., Paudel, P. K., Jnawali, S. R., Neupane, P. R., \& Köhl, M., 2017. Can forest fragmentation and configuration work as indicators of human-wildlife conflict? Evidences from human death and injury by wildlife attacks in Nepal. Ecological Indicators, 80, 74-83. https://doi.org/10.1016/j.ecolind.2017.04.037

Acharya, K. P., Paudel, P. K., Neupane, P. R., \& Köhl, M., 2016. Human-wildlife conflicts in Nepal: Patterns of human fatalities and injuries caused by large mammals. PLOS ONE, 11(9), 1-18. https://doi.org/10.1371/journal.pone.0161717

Aryal, C., 2016. Evaluation of suitability of Triyuga forest of Eastern Nepal as potential Tiger (Panthera tigris tigris, Linneus, 1758) habitat. Tribhuvan University. 1-48.

Aryal, C., Subedi, N., \& Aryal, P.C., 2020. Occupancy of Mammalian Carnivore in Triyuga Forest of Eastern Lowland, Nepal. Journal of Environment Sciences, 6(1), 52-59.

Athreya, V., Odden, M., Linnell, J. D. C., Krishnaswamy, J., \& Karanth, U., 2013. Big Cats in Our Backyards: Persistence of Large Carnivores in a Human Dominated Landscape in India. PLoS ONE, 8(3), 2 9. https://doi.org/10.1371/journal.pone.0057872

Bargali, H. S., Akhtar, N., \& Chauhan, N. P. S., 2005. Characteristics of sloth bear attacks and human casualties in North Bilaspur Forest Division, Chhattisgarh, India. Ursus, 16(2), 263-267. https://doi.org/10.2192/1537-6176(2005)016[0263:COSBAA]2.0.CO;2

Barua, M., Bhagwat, S. A., \& Jadhav, S., 2013. The hidden dimensions of human - wildlife conflict: Health impacts , opportunity and transaction costs. Biological Conservation, 157, 309-316. https://doi.org/10.1016/j.biocon.2012.07.014

Bhattarai, B. R., \& Fischer, K., 2014. Human-tiger Panthera tigris conflict and its perception in Bardia National Park, Nepal. Oryx, 48(4), 522-528. https://doi.org/10.1017/S0030605313000483

Bhattarai, S., Pant, B., \& Timalsina, N., 2017. Conservation Without Participation: Deterimental Effect of Escaping People's Participation in Protected Area Management in Nepal. In S. A. Mukul \& A. Z. M. Rashid (Eds.), Protected Areas: Policies, Management and Future Directions (pp. 83-103). Nova Publishers, New York.

Bibi, S. S., Minhas, R. A., Awan, M. S., Ali, U., \& Dar, N. I., 2013. Study of ethno-carnivore relationship in Dhirkot, Azad Jammu and Kashmir (Pakistan). Journal of Animal and Plant Sciences, 23(3), 854 859. 
Can, Ö. E., D’Cruze, N., Garshelis, D. L., Beecham, J., \& Macdonald, D. W., 2014. Resolving Human-Bear Conflict: A Global Survey of Countries, Experts, and Key Factors. Conservation Letters, 7(6), 501513. https://doi.org/10.1111/conl.12117

Chaudandigadhi Municipality, 2020. Chaudandigadhi Municipality, Office of Prime Executive, Province No.

1, Government of Nepal. Accessed from https://chaudandigadhimun.gov.np/en/node/4 [accessed on: 20 July 2020].

Constant, N. L., Bell, S., \& Hill, R. A., 2015. The impacts, characterisation and management of humanleopard conflict in a multi-use land system in South Africa. Biodiversity and Conservation, 24(12), 2967-2989. https://doi.org/10.1007/s10531-015-0989-2

Dickman, A. J., 2010. Complexities of conflict: the importance of considering social factors for effectively resolving human-wildlife conflict. Animal Conservation, 13(5), 458-466. https://doi.org/10.1111/j.1469-1795.2010.00368.x

Fernando, P., Wikramanayake, E., Weerakoon, D., \& Jayasinghe, L. K. A., 2005. Perceptions and patterns of human - elephant conflict in old and new settlements in Sri Lanka: insights for mitigation and management. Biodiversity and Conservation, 14, 2465-2481. https://doi.org/10.1007/s10531-0040216-Z

Garcia, K. C., Joshi, H. M., \& Dharaiya, N., 2016. Assessment of human-sloth bear conflicts in North Gujarat, India. Ursus, 27(1), 5. https://doi.org/10.2192/URSUS-D-15-00012.1

Gurung, B., Smith, J.J. L. D., McDougal, C., Karki, J. B., \& Barlow, A., 2008. Factors associated with humankilling tigers in Chitwan National Park, Nepal. Biological Conservation, 141(12), 3069-3078. https://doi.org/10.1016/j.biocon.2008.09.013

Hoare, R. E., 1999. Determinants of human-elephant conflict in a land-use mosaic. Journal of Applied Ecology, 36(5), 689-700. https://doi.org/10.1046/j.1365-2664.1999.00437.x

Inskip, C., \& Zimmermann, A., 2009. Human-felid conflict: a review of patterns and priorities worldwide. Oryx, 43(01), 18. https://doi.org/10.1017/S003060530899030X

Jnawali, S., Baral, H., Lee, S., Acharya, K., Upadhyay, G., Pandey, M., Shrestha, R., Joshi, D., Laminchhane, B., Griffiths, J., Khatiwada, A., Subedi, N., \& Amin, R., 2011. The Status of Nepal's Mammals: The National Red List Series. Department of National Parks and Wildlife Conservation, Kathmandu,Nepal. 1-266.

Joshi, A. R., Smith, J. L. D., \& Garshelis, D. L., 1999. Sociobiology of the myrmecophagous sloth beer in Nepal. Canadian Journal of Zoology, 77(11), 1690-1704. https://doi.org/10.1139/z99-131

Kabir, M., Ghoddousi, A., Awan, M. S., \& Awan, M. N., 2014. Assessment of human-leopard conflict in Machiara National Park, Azad Jammu and Kashmir, Pakistan. European Journal of Wildlife 
Research, 60(2), 291-296. https://doi.org/10.1007/s10344-013-0782-z

Karanth, K. K., \& Nepal, S. K., 2012. Local Residents Perception of Benefits and Losses From Protected Areas in India and Nepal. Environmental Management, 49(2), 372-386. https://doi.org/10.1007/s00267-011-9778-1

Khadka, N. B., Acharya, P., \& Chaudhary, C. N., 1997. Ecology and conservation of Bos gaurus in Belaka forest of Udaypur District, Nepal. Banko Janakari, 7(2), 39-42. https://doi.org/10.3126/banko.v7i2.18114

Kusi, N., Sillero-Zubiri, C., Macdonald, D. W., Johnson, P. J., \& Werhahn, G., 2020. Perspectives of traditional Himalayan communities on fostering coexistence with Himalayan wolf and snow leopard. Conservation Science and Practice, 2(3). https://doi.org/10.1111/csp2.165

Lillesø, J. P. B., Shrestha, T. B., Dhakal, L. P., Nayaju, R. P., \& Shrestha, R., 2005. The map of potential vegetation of Nepal: a forestry/agroecological/biodiversity classification system. Development and Environment, (2), 76.

Mir, Z. R., Noor, A., Habib, B., \& Veeraswami, G. G., 2015. Attitudes of local people toward wildlife conservation: A case study from the Kashmir Valley. Mountain Research and Development, 35(4), 392-400. https://doi.org/10.1659/MRD-JOURNAL-D-15-00030.1

Neupane, D., Johnson, R. L., \& Risch, T. S., 2013. Temporal and spatial patterns of human-elephant conflict in Nepal. 2013 International Elephant \& Rhino Conservation \& Research Symposium Proceedings, 1-11.

Newing, H., Eagle, C. M., Puri, R. K., \& Watson, C. W., 2010. Conducting research in conservation: Social science methods and practice. https://doi.org/10.4324/9780203846452

Pandey, P., Shaner, P. J. L., \& Sharma, H. P., 2016. The wild boar as a driver of human-wildlife conflict in the protected park lands of Nepal. European Journal of Wildlife Research, 62(1), 103-108. https://doi.org/10.1007/s10344-015-0978-5

Redpath, S. M., Young, J., Evely, A., Adams, W. M., Sutherland, W. J., Whitehouse, A., Amar, A., Lambert, R. A., Linnell, J. D. C., Watt, A., \& Gutiérrez, R. J., 2013. Understanding and managing conservation conflicts. Trends in Ecology and Evolution, 28(2), 100-109. https://doi.org/10.1016/j.tree.2012.08.021

Richard, A. F., Goldstein, S. J., \& Dewar, R. E., 1989. Weed macaques: The evolutionary implications of macaque feeding ecology. International Journal of Primatology, 10(6), 569-594. https://doi.org/10.1007/BF02739365

Røskaft, E., Bjerke, T., Kaltenborn, B., Linnell, J. D. C., \& Andersen, R., 2003. Patterns of self-reported fear towards large carnivores among the Norwegian public. Evolution and Human Behavior, 24(3), 
184-198. https://doi.org/10.1016/S1090-5138(03)00011-4

Seoraj-Pillai, N., \& Pillay, N., 2017. A meta-analysis of human-wildlife conflict: South African and global perspectives. Sustainability (Switzerland), 9(1), 1-21. https://doi.org/10.3390/su9010034

Sherchan, R., \& Bhandari, A., 2017. Status and trends of human-wildlife conflict: A case study of Lelep and Yamphudin region, Kanchenjunga Conservation Area, Taplejung, Nepal. Conservation Science, 5(1), 19-25. https://doi.org/10.3126/cs.v5i1.24296

Shrestha, R., 2007. A Case Study on Human-Wildlife Conflict in Nepal: with Particular Reference to HumanElephant Conflict in Eastern and Western Terai Regions. 1-63.

Studsrød, J. E., \& Wegge, P., 1995. Park-People Relationships: The Case of Damage Caused by Park Animals Around the Royal Bardia National Park, Nepal. Environmental Conservation, 22(2), 133 142. https://doi.org/10.1017/S0376892900010183

Sukumar, R., 1990. Ecology of the Asian elephant in southern India. II. Feeding habits and crop raiding patterns. Journal of Tropical Ecology, 6(1), 33-53. https://doi.org/10.1017/S0266467400004004

Thapa, S., 2010. Effectiveness of crop protection methods against wildlife damage: A case study of two villages at Bardia National Park, Nepal. Crop Protection, 29(11), 1297-1304. https://doi.org/10.1016/j.cropro.2010.06.015

Treves, A., \& Karanth, K. U., 2003. Human-Carnivore Conflict and Perspectives on Carnivore Management Worldwide. Conservation Biology, 17(6), 1491-1499. https://doi.org/10.1111/j.15231739.2003.00059.x

White, P. C. L., Jennings, N. V., Renwick, A. R., \& Barker, N. H. L., 2005. REVIEW: Questionnaires in ecology: a review of past use and recommendations for best practice. Journal of Applied Ecology, 42(3), 421-430. https://doi.org/10.1111/j.1365-2664.2005.01032.x

Yoganand, K., Johnsingh, A. J. T., \& Rice, C. G., 2005.Evaluating Panna National Park with special reference to the ecology of Sloth Bear. Wildlife Institute of India, Dehradun, India. Final project report, i-viii.

Yoganand, K., Rice, C., Johnsingh, A., \& Seidensticker, J., 2006. Is the Sloth Bear in India Secure? A Preliminary Report on Distribution, Threats and Conservation Requirements. Journal of The Bombay Natural History Society, 103(2-3), 57. 